\title{
Subjective reactions to music and brainwave rhythms
}

\author{
JAMES L. WALKER \\ Brandon University, Brandon, Manitoba, Canada R7A 6 A9
}

The relationship between subjective reactions to music and EEG frequencies over left and right occipital sites was studied in groups of musicians and nonmusicians. Self-reports of attentiveness during music listening, familiarity with the music, and emotional reactions to the music all correlated moderately to substantially with various EEG frequency measures. The majority of significant correlations were between self-reports and direct measures of EEG activity in the slower theta and delta bands, while music minus silence EEG measures in the alpha and beta bands provided superior correlates of subjective reactions. These results suggest that EEG techniques may be useful in increasing understanding of brain mechanisms associated with music perception, and that it may prove to be ultimately possible to account for sizable segments of the variance of aesthetic reactions to musical stimuli in terms of EEG measures of brain activity.

Since the initial description of human brainwaves (Berger, 1929), there have been numerous studies relating the human electroencephalogram (EEG) to sensory input, attention, behavior, and various cognitive processes (Shagass, 1972). Many studies of EEG activity during nonlinguistic auditory input have been limited to the use of simple sounds such as pure tones. In a recent report, Wagner (1975a) reviewed the limited literature relating human brainwaves to the perception of music and suggested that additional EEG studies might be helpful in increasing our understanding of the brain mechanisms underlying perception of complex musical stimuli.

The purpose of the present study was to determine if EEG measures of the electrical activity of the brain are systematically related to subjective reactions to musical stimuli. To our knowledge, the present study represents one of the few published demonstrations of significant relationships between subjective reactions to musical stimuli and EEG measures of brainwave activity.

\section{METHOD}

\section{Subjects}

Twenty-four right-handed undergraduate students from Brandon University participated in the study. Twelve of the subjects were advanced undergraduate majors drawn from the faculty of music. The remaining subjects were nonmusicians selected from an introductory psychology course. An equal number of males and females were represented in both groups. All potential

This study was supported by Brandon University President's NRC Grant 2374. Address requests for reprints to: J. L. Walker, Department of Psychology, Brandon University, Brandon, Manitoba, Canada, R7A 6A9. I wish to thank Professor Alan Ehnes from the Faculty of Music at Brandon University for assistance in conducting this study. subjects were given an initial screening, and any student reporting a preference for the left hand was not included in the study. The subjects ranged in age from 18 to 32 years. The mean age of the musicians was 21.2 years, and the mean age of the nonmusicians was 21.8 years.

\section{Procedures}

EEG recordings were collected during three aural conditions, including two musical conditions and a period of silence. The first musical stimulus consisted of a 1.63-min recording of Mahler's Symphony No. 5, fourth movement "Adagietto," final $F$ major theme statement to end of movement. This slow and generally peaceful movement was scored for harp and strings and was from a recording by the Chicago Symphony Orchestra (London, CSA-2228). The second musical condition was $1.75 \mathrm{~min}$ long and represented an instrumental interlude from "Gypsy" by Uriah Heap ("Uriah Heap," Mercury, SR6129). It consisted of a repetitive pattern in parallel fifths played on electric guitars with a heavy recurring rhythmic pattern on drum set and modal flavored blues solo on electric organ. Both musical selections were exclusively instrumental. The music stimuli were recorded once in the monaural mode onto magnetic tape and played to each subject at a constant comfortable listening level over a Realistic stethoscope headset. The silence conditions consisted of the playing of a 2-min segment of blank tape through the audio system and the earphones. The earphones were reversed for every other subject so that any asymmetries in the tape or earphones would be balanced over ears. The order of the stimulus conditions was also completely counterbalanced between subjects so that each stimulus appeared equally often on the first, second, and third stimulus trial.

Electrodes were attached over left and right hemisphere occipital lobe locations at $\mathrm{O}_{1}$ and $\mathrm{O}_{2}$ of the 10-20 International Electrode Placement System. Recordings were bipolar, with each electrode referenced to the vertex electrode at $C_{z}$. Prior to recording, the impedance of each electrode was tested, and any electrode showing an impedance of $8 \mathrm{k} \Omega$ or larger was reapplied until the impedance was smaller than $8 \mathrm{k} \Omega$. The ground electrode was placed on the left ear lobe. All EEG recordings were done on a Grass Model 79C polygraph. Recording procedures are described in more detail elsewhere (Walker \& Ehnes, Note 1).

During the experiment, the subjects sat in an upright position in a recliner chair with their eyes closed. The subjects were housed in a sound-deadened room, and all recording instrumentation was 
located in an adjoining room. After each musical stimulus was presented, the experimenter reentered the experimental room and administered the subjective reaction scale.

EEG records were scored using the manual period analysis method developed by Sulg (1969). Manual scoring of the EEG tracings was done independently of the scoring for the subjective response scales so that the experimenter was blind to the subjective responses during all EEG scoring. Because of practical restric tions, it was not possible to analyze all of the EEG records collected during the course of the study. The results described below represent an analysis of EEG frequencies during the first $5 \mathrm{sec}$, the $5 \mathrm{sec}$ following the midpoint, and the last $5 \mathrm{sec}$ of each stimulus condition. In all, a total of $15 \mathrm{sec}$ of EEG tracings were analyzed for each subject at each recording site during each of the three aural conditions. Measures were collected describing the percentage of four basic EEG frequency classes. Percent beta represents percent time of $14-30-\mathrm{Hz}$ activity, percent alpha corresponds to percent time of $8-13-\mathrm{Hz}$ activity, percent theta reflects 4-7- $\mathrm{Hz}$ activity, and percent delta represents slow 1-3-Hz EEG frequencies.

Immediately following the end of each musical stimulus, a rating scale was given to each subject, allowing them to evaluate a number of their subjective reactions to the music they had just heard. The rating scale consisted of eight scales with descriptive adjectives on both ends of the scale. The bipolar adjectives were separated by a $13-\mathrm{cm}$ line, and subjects were asked to put a slash through each line at a point which corresponded to their subjective reaction. One end of each scale was arbitrarily defined as the zero point, and the maximum score on each scale was $13 \mathrm{~cm}$. The distance of the slash from the zero end of the scale was measured in millimeters and expressed the person's score on that scale. The following items were included on the rating sheet: "1. How familiar was the musical selection you have just heard? (Put a slash through the line at a point which corresponds to your general evaluation of the familiarity of the music.): unfamiliar-familiar; 2 . How would you describe the music you have just heard? (Put a slash through each line at a point which corresponds to your general impression.): comforting-disturbing; depressing-exciting; happy-sad; unpleasant-pleasant. 3. During the music I: listened atteritively to the music-played little attention to the music. 4 . I personally found the music to be: irritating-soothing; 5. The music made me feel more: relaxed-tense.

At the completion of the study, the eight EEG indices and the scores on all eight rating scales for each subject were punched onto computer cards and a Pearson product moment correlation matrix was computed using computer program BMD12D (Dixon, 1973). Several correlational matrices were computed in this manner, including the matrix for intercorrelations between measures on all subjects to the classical music, intercorrelations for all subjects for the rock music condition, the cor- relational matrix for nonmusicans with musical condition collapsed, and also the matrix for musicians across both music conditions.

\section{RESULTS}

\section{Classical Music}

Table 1 presents correlations between subjective reactions to the classical music and EEG percent activity times in each bandwidth during the classical music. Slow-wave delta activity over the left occipital site showed a correlation of $\mathrm{r}=-.424(\mathrm{~N}=23$, $\mathrm{p}<.05$ ) with scores on the "unpleasant-pleasant" scale. The sign of this correlation indicated that subjects giving ratings in the "unpleasant" direction tended to produce more delta activity at the left occipital site. Delta activity at the right occipital site showed a similar correlation with the "unpleasantpleasant" scale $(r=-.437, \mathrm{~N}=23, \mathrm{p}<.05)$. At both recording sites, high delta wave producers showed a tendency to rate the classical music as more unpleasant. The mean score on the "unpleasantpleasant" scale was $10.7(\mathrm{SD}=1.9)$. Since this scale was scored with "unpleasant" at the zero end of the scale, the average of 10.7 indicates a mean evaluation of the classical music toward the "pleasant" end of the scale.

Subjective reports of how attentive the subjects were to the music correlated significantly with four separate EEG measures. Theta activity at both left and right hemisphere occipital sites correlated significantly with the "listened attentively to the musicpayed little attention to the music" scale. The negative sign of both of these correlations indicated that high theta producers tended to report paying less attention to the music. The mean response on the attentiveness scale was 10.1 $(\mathrm{SD}=1.96)$. Subjective reports of attentiveness also were found to correlate significantly with the amount of delta and alpha activity over the right occipital site. The correlation between attentiveness and $\mathrm{O}_{2}$ delta was $\mathrm{r}=-.613$ $(\mathrm{N}=24, \mathrm{p}<.01)$. The sign of the correlation indicated that high delta producers tended to report

Table 1

Correlations of Subjective Reactions and EEG Percent Activity Times During Classical Music

\begin{tabular}{|c|c|c|c|c|c|c|c|c|c|}
\hline \multirow[b]{2}{*}{ Site } & \multirow[b]{2}{*}{ Band } & \multicolumn{8}{|c|}{ Subjective Reaction Scale } \\
\hline & & 1 & 2 & 3 & 4 & 5 & 6 & 7 & 8 \\
\hline $0_{1}$ & $\begin{array}{l}\text { Delta } \\
\text { Theta } \\
\text { Alpha } \\
\text { Beta }\end{array}$ & $\begin{array}{r}-.13 \\
.23 \\
-.13 \\
-.01\end{array}$ & $\begin{array}{r}-.01 \\
.26 \\
-.09 \\
-.04\end{array}$ & $\begin{array}{r}-.08 \\
-.15 \\
-.05 \\
.04\end{array}$ & $\begin{array}{r}-.06 \\
.16 \\
-.14 \\
-.04\end{array}$ & $\begin{array}{l}-.42 * \\
-.05 \\
-.06 \\
-.08\end{array}$ & $\begin{array}{l}-.31 \\
-.62 * * \\
.23 \\
-.14\end{array}$ & $\begin{array}{r}-.20 \\
.12 \\
-.02 \\
-.22\end{array}$ & $\begin{array}{r}.03 \\
-.28 \\
.23 \\
.02\end{array}$ \\
\hline $\mathrm{O}_{2}$ & $\begin{array}{l}\text { Delta } \\
\text { Theta } \\
\text { Alpha } \\
\text { Beta }\end{array}$ & $\begin{array}{r}-.15 \\
.15 \\
-.12 \\
.01\end{array}$ & $\begin{array}{r}-.03 \\
.23 \\
-.16 \\
.02\end{array}$ & $\begin{array}{r}.00 \\
-.18 \\
.09 \\
-.01\end{array}$ & $\begin{array}{r}.15 \\
.12 \\
-.05 \\
-.11\end{array}$ & $\begin{array}{l}-.44 * \\
-.03 \\
-.05 \\
-.03\end{array}$ & $\begin{array}{c}-.61^{* *} \\
-.58^{* *} \\
.42^{*} \\
-.22\end{array}$ & $\begin{array}{r}-.21 \\
.05 \\
-.04 \\
-.13\end{array}$ & $\begin{array}{r}.01 \\
-.17 \\
.28 \\
-.08\end{array}$ \\
\hline
\end{tabular}

Note-Subjective Reaction Scale identification: 1, unfamiliar-familiar; 2, comforting-disturbing; 3, depressing-exciting; 4, happy-sad; 5, unpleasant-pleasant; 6, listened attentively-payed little attention; 7, irritating-soothing; 8, relaxed-tense.

${ }^{*} p<.05$

$* * p<.01$ 
paying less attention to the music. The correlating between right occipital alpha activity and reports of attentiveness was $\mathrm{r}=.418(\mathrm{~N}=24, \mathrm{p}<.05)$. This correlation suggested that high attentiveness to the music was associated with increased alpha production.

In an attempt to determine if music-induced EEG changes were associated with subjective reactions, additional EEG scores were computed reflecting EEG percent activity time during music minus EEG percent activity time during silence. Table 2 presents the mean difference scores (music-silence) for all subjects to both the classical and rock music. The $t$ tests reported in Table 2 tested the hypothesis that the mean difference between music and silence was zero. The matrix resulting from correlating the EEG difference score for classical music with the subjective reactions to the classical music is presented in Table 3. At the left occipital site, a statistically significant correlation of $-.58(\mathrm{~N}=24, \mathrm{p}<.01)$ indicated that the larger the difference between percent theta during the music as compared to silence, the more relaxed the subjects rated themselves. Sixteen subjects showed greater levels of theta activity during the classical music as compared to the silence condition. The mean difference between percent theta during music minus percent theta during silence was $2.29(\mathrm{SD}=5.8)$. The difference between $\mathrm{O}_{1}$ alpha during music and silence correlated significantly with Scale 2 ("comforting-disturbing"). This correlation $(r=.40, N=23), p<.05)$ indicated that ratings toward the "comforting" end of the scale were associated with larger differences in $\mathrm{O}_{1}$ alpha during music as compared to silence. Fifteen subjects had larger alpha times during silence than during music $\left(\overline{\mathrm{X}}_{\mathrm{d}}=-.499, \mathrm{SD}=9.64\right)$. Scale 2 also correlated significantly $(r=-.64, \mathrm{~N}=23$, $p<.01$ ) with the beta difference at $O_{1}$. This negatively signed correlation indicated that larger beta differences were associated with increased ratings of being disturbed by the music. Ten subjects showed more beta activity at $\mathrm{O}_{1}$ during the music as compared to during the silence $\left(\bar{X}_{d}=2.18, S D=8.34\right)$. Six significant correlations were present for EEG measures at the right hemisphere occipital site. Both difference scores for $\mathrm{O}_{2}$ alpha and $\mathrm{O}_{2}$ beta correlated significantly with Scale 1 (unfamiliar-familiar). The correlation of $-.55(\mathrm{~N}=24, \mathrm{p}<.01)$ for change in percent alpha and Scale 1 indicated that greater differences in $\mathrm{O}_{2}$ alpha during music as compared to

Table 2

Mean Difference Scores Between Music and Silence for EEG Frequencies

\begin{tabular}{|c|c|c|c|c|c|c|c|}
\hline \multirow[b]{2}{*}{ Site } & \multirow[b]{2}{*}{ Band } & \multicolumn{3}{|c|}{ Classical Music } & \multicolumn{3}{|c|}{ Rock Music } \\
\hline & & $\overline{\mathbf{x}}_{\mathbf{d}}$ & $\mathbf{s}_{\mathbf{d}}$ & $\mathrm{t}$ & $\overline{\mathbf{x}}_{\mathbf{d}}$ & $\mathbf{s}_{\mathbf{d}}$ & $\mathbf{t}$ \\
\hline $0_{1}$ & $\begin{array}{l}\text { Delta } \\
\text { Theta } \\
\text { Alpha } \\
\text { Beta }\end{array}$ & $\begin{array}{r}1.82 \\
2.29 \\
-4.99 \\
2.18\end{array}$ & $\begin{array}{l}5.6 \\
5.8 \\
9.6 \\
8.3\end{array}$ & $\begin{array}{l}1.59 \\
1.92 * \\
2.55 \dagger \\
1.28\end{array}$ & $\begin{array}{r}2.64 \\
2.02 \\
-5.90 \\
2.27\end{array}$ & $\begin{array}{l}3.7 \\
5.4 \\
7.8 \\
8.4\end{array}$ & $\begin{array}{l}3.47 \dagger \dagger \\
1.84^{*} \\
3.71 \dagger \dagger \\
1.32\end{array}$ \\
\hline $0_{2}$ & $\begin{array}{l}\text { Delta } \\
\text { Theta } \\
\text { Alpha } \\
\text { Beta }\end{array}$ & $\begin{array}{r}2.80 \\
3.31 \\
-2.82 \\
1.13\end{array}$ & $\begin{array}{l}5.2 \\
5.3 \\
9.0 \\
6.7\end{array}$ & $\begin{array}{l}2.64 \dagger \\
3.06 \dagger \dagger \\
1.53 \\
.82\end{array}$ & $\begin{array}{r}3.12 \\
3.08 \\
-6.67 \\
.48\end{array}$ & $\begin{array}{r}4.7 \\
6.7 \\
9.2 \\
12.5\end{array}$ & $\begin{array}{c}3.25 \dagger \dagger \\
2.25 * * \\
3.55 \dagger \dagger \\
.19\end{array}$ \\
\hline
\end{tabular}

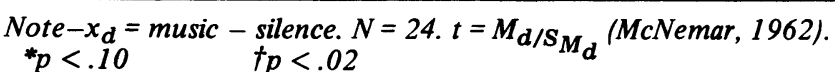

${ }^{*} p<.10 \quad t p<.02$

$* * p<.05 \quad t+p<.01$

Table 3

Correlations of Subjective Reactions and EEG Difference Scores (Classical Music Minus Silence) for Musicians and Nonmusicians

\begin{tabular}{|c|c|c|c|c|c|c|c|c|c|}
\hline \multirow[b]{2}{*}{ Site } & \multirow[b]{2}{*}{ Band } & \multicolumn{8}{|c|}{ Subjective Rating Scale } \\
\hline & & 1 & 2 & 3 & 4 & 5 & 6 & 7 & 8 \\
\hline $0_{1}$ & $\begin{array}{l}\text { Delta } \\
\text { Theta } \\
\text { Alpha } \\
\text { Beta }\end{array}$ & $\begin{array}{r}-.16 \\
.35 \\
-.16 \\
.15\end{array}$ & $\begin{array}{c}-.02 \\
.14 \\
.40 * \\
-.64 * *\end{array}$ & $\begin{array}{r}-.05 \\
-.19 \\
-.12 \\
.27\end{array}$ & $\begin{array}{r}.00 \\
-.03 \\
-.18 \\
-.09\end{array}$ & $\begin{array}{r}-.22 \\
.01 \\
.12 \\
-.10\end{array}$ & $\begin{array}{r}-.05 \\
-.36 \\
-.28 \\
.36\end{array}$ & $\begin{array}{r}-.07 \\
.22 \\
.03 \\
-.10\end{array}$ & $\begin{array}{l}-.04 \\
-.58 * * \\
.31 \\
-.09\end{array}$ \\
\hline $\mathbf{O}_{2}$ & $\begin{array}{l}\text { Delta } \\
\text { Theta } \\
\text { Alpha } \\
\text { Beta }\end{array}$ & $\begin{array}{c}-.06 \\
-.13 \\
-.55^{* *} \\
.47 *\end{array}$ & $\begin{array}{r}.05 \\
.05 \\
-.14 \\
-.01\end{array}$ & $\begin{array}{r}-.21 \\
-.19 \\
.19 \\
-.27\end{array}$ & $\begin{array}{r}.14 \\
-.10 \\
.32 \\
-.44 *\end{array}$ & $\begin{array}{r}-.17 \\
-.24 \\
.38 \\
.12\end{array}$ & $\begin{array}{r}-.29 \\
-.35 \\
.21 \\
.07\end{array}$ & $\begin{array}{l}-.01 \\
-.15 \\
-.42 * \\
.07\end{array}$ & $\begin{array}{l}-.23 \\
-.10 \\
.63^{* *} \\
-.44^{*}\end{array}$ \\
\hline
\end{tabular}

Note-Subjective Reaction Scale identification: 1, unfamiliar-familiar; 2, comforting-disturbing; 3, depressing-exciting; 4, happy-sad; 5, unpleasant-pleasant; 6 , listened attentively-payed little attention; 7 , irritating-soothing; 8 , relaxed-tense.

$* p<.05$

$* * p<.01$ 
silence were associated with ratings of "unfamiliarity" with the music. The mean difference score for $\mathrm{O}_{2}$ alpha was $-2.82(\mathrm{SD}=8.96)$. Fifteen subjects showed more alpha activity during silence than during the music. The $\mathrm{O}_{2}$ beta difference scores correlated $.47(\mathrm{~N}=24, \mathrm{p}<.05)$ with scores on Scale 1 . This correlation indicated that large difference scores in percent beta were associated with increased ratings of familiarity with the music. The mean difference in $\mathrm{O}_{2}$ beta was $1.13(\mathrm{SD}=6.73)$ and 15 subjects showed more beta activity during the music as compared to during silence. Difference scores for $\mathrm{O}_{2}$ alpha and beta also correlated significantly with Scale 8 (relaxed-tense). The correlation of $.63(\mathrm{~N}=$ $24, p<.01)$ showed that larger differences in percent alpha were associated with ratings of increased tenseness while the correlation of $-.44(\mathrm{~N}=24$, $\mathrm{p}<.01$ ) between data difference scores and Scale 8 indicated that small differences in beta during music and silence were also associated with increased ratings toward the "tense" end of the scale. Modest correlations were also obtained between difference scores for $\mathrm{O}_{2}$ alpha $(\mathrm{r}=-.42, \mathrm{~N}=24, \mathrm{p}<.05)$ and Scale 7 (irritating-soothing) and for $\mathrm{O}_{2}$ beta difference scores and Scale 4 (happy-sad) $(r=-.44$, $\mathrm{N}=22, \mathrm{p}<.05$ ). These correlations indicated that large $\mathrm{O}_{2}$ alpha difference scores were associated with ratings toward the "irritating" end of Scale 7, while large differences in $\mathrm{O}_{2}$ beta were correlated with ratings of "sad" on Scale 1.

\section{Rock Music}

Direct EEG measures collected during the rock music showed little relationship with the subjective reaction scales. With only one exception, all correlations were statistically nonsignificant. The exception was the $r=.420(\mathrm{~N}=24, \mathrm{p}<.05)$ observed between delta activity at the right occipital site and the attentiveness scale. The correlation indicated that high attentiveness was associated with high delta production.
EEG difference scores between the rock music and silence were also poor predictors of subjective reactions to the rock music. Only two of the EEG difference scores correlated significantly with the subjective reaction scales. The difference between $\mathrm{O}_{1}$ theta during music and silence showed a correlation of $-.45(\mathrm{~N}=23, \mathrm{p}<.05)$ with Scale 5 (unpleasant-pleasant). A large theta difference score was associated with "unpleasant" ratings. The difference score for $\mathrm{O}_{2}$ theta was also found to correlate modestly $(r=-.44, \mathrm{~N}=24, \mathrm{p}<.05)$ with Scale 7 (irritating-soothing). High $\mathrm{O}_{2}$ theta difference scores were associated with ratings of irritation.

\section{Nonmusicians vs. Musicians}

Additional correlational matrices were computed using nonmusician vs. musician as the primary grouping variable with scores under the two musical conditions collapsed. In the case of the musicians, none of the correlations between subjective reactions and direct EEG measures were statistically significant. Six statistically significant correlations were, however, observed for the nonmusicians. The complete correlation matrix is presented in Table 4. Scores on the "unfamiliar-familiar" scale correlated with three EEG measures. A correlation of $r=.549(\mathrm{~N}=24, \mathrm{p}<.01)$ was obtained between left hemisphere theta activity and the familiarity scale. This correlation indicated that reports of high familiarity with the music were associated with high theta production. A negatively signed correlation was observed between left hemisphere alpha activity and familiarity $(\mathrm{r}=-.505, \mathrm{~N}=24, \mathrm{p}<.02)$. This correlation indicated that low familiarity scores were associated with high alpha production. A similar correlation was observed between familiarity scores and alpha activity at the right hemisphere $(r=-.594$, $\mathrm{N}=24, \mathrm{p}<.01$ ). Again, the indication was that low familiarity with the music was associated with high alpha production. The mean score on the familiarity scale for the musicians was $7.06(S D=4.8)$, while

Table 4

Correlations of Subjective Reactions and EEG Activity Times for Nonmusicians During Rock and Classical Music

\begin{tabular}{|c|c|c|c|c|c|c|c|c|c|}
\hline \multirow[b]{2}{*}{ Site } & \multirow[b]{2}{*}{ Band } & \multicolumn{8}{|c|}{ Subjective Rating Scale } \\
\hline & & 1 & 2 & 3 & 4 & 5 & 6 & 7 & 8 \\
\hline 0, & $\begin{array}{l}\text { Delta } \\
\text { Theta } \\
\text { Alpha } \\
\text { Beta }\end{array}$ & $\begin{array}{l}.07 \\
.55 \dagger \\
-.50 * * \\
.22\end{array}$ & $\begin{array}{r}-.20 \\
.04 \\
-.29 \\
.17\end{array}$ & $\begin{array}{r}-.25 \\
-.18 \\
.33 \\
-.40\end{array}$ & $\begin{array}{r}-.21 \\
-.25 \\
.33 \\
-.28\end{array}$ & $\begin{array}{r}-.34 \\
.01 \\
-.11 \\
-.01\end{array}$ & $\begin{array}{l}-.18 \\
-.46^{*} \\
.25 \\
-.08\end{array}$ & $\begin{array}{r}-.18 \\
.10 \\
.12 \\
-.07\end{array}$ & $\begin{array}{l}-.02 \\
-.42^{*} \\
.35 \\
-.02\end{array}$ \\
\hline $0_{2}$ & $\begin{array}{l}\text { Delta } \\
\text { Theta } \\
\text { Alpha } \\
\text { Beta }\end{array}$ & $\begin{array}{c}.29 \\
.36 \\
-.59 \dagger \\
.25\end{array}$ & $\begin{array}{r}-.05 \\
.00 \\
-.28 \\
.16\end{array}$ & $\begin{array}{r}-.11 \\
-.32 \\
.38 \\
-.37\end{array}$ & $\begin{array}{r}-.32 \\
-.22 \\
.34 \\
-.23\end{array}$ & $\begin{array}{r}-.03 \\
-.10 \\
-.13 \\
.05\end{array}$ & $\begin{array}{l}-.33 \\
-.55 \dagger \\
.33 \\
-.02\end{array}$ & $\begin{array}{l}-.01 \\
-.01 \\
-.09 \\
-.07\end{array}$ & $\begin{array}{r}-.15 \\
-.30 \\
.39 \\
-.01\end{array}$ \\
\hline
\end{tabular}

Note-Subjective Reaction Scale identification: 1, unfamiliar-familiar; 2, comforting-disturbing; 3, depressing-exciting; 4, happy-sad; 5 , unpleasant-pleasant; 6 , listened attentively-payed little attention; 7, irritating-soothing; 8 , relaxed-tense.

${ }^{*} p<.05$

$* * p<.02$ 
the nonmusicians had a mean score of $3.96(\mathrm{SD}=3.5)$ on this scale, indicating less average familiarity with the musical selections among the nonmusicians than among the musicians.

The attentiveness scale correlated with two EEG measures among the nonmusicians. The correlation between this scale and theta over the left hemisphere was $r=-.465(\mathrm{~N}=24, \mathrm{p}<.05)$. Low attentiveness was thus associated with high theta production. The attentiveness scores also correlated with theta over the right hemisphere $(r=-.54, \mathrm{~N}=24, \mathrm{p}<$ .01 ), again indicating an association between low attentiveness scores and high theta production. The mean attentiveness score in the musicians across both music conditions was $9.4(\mathrm{SD}=3.1)$, and the mean score for the nonmusicians was 9.8 $(\mathrm{SD}=1.7)$. Theta activity at the left occipital site was also found to correlate with "the music made me feel more: relaxed-tense" $(\mathrm{r}=-.416, \mathrm{~N}=24, \mathrm{p}<.05)$. The sign of the correlation indicated that reports of relaxation were associated with high theta production. The mean score for the musicians on the "relaxedtense" scale was $5.4(\mathrm{SD}=3.97)$, and a mean score of 5.7 (SD = 3.66) was observed on this scale for the nonmusicians.

Table 5 presents the mean difference scores, their standard deviations, and $t$ values testing the hypotheses that the $\overline{\mathrm{X}}_{\mathrm{d}}$ was zero for musicians and nonmusicians. Eleven of the 16 mean differences between music and silence were found to be significantly greater than zero.

The difference scores between music minus silence proved to be weak predictors of subjective reactions when the data was categorized according to whether subjects were musicians and nonmusicians. In the case of musicians, only two correlations reached significance: the $\mathrm{O}_{1}$ beta difference scores correlated $-.46(\mathrm{~N}=24, \mathrm{p}<.05)$ with Scale 2 (comfortingdisturbing), while $\mathrm{O}_{1}$ beta difference scores also correlated with responses on Scale 3 (depressingexciting) $(r=.47, \mathrm{~N}=24, \mathrm{p}<.05)$. The former correlation indicated that large differences in $\mathrm{O}_{1}$ beta during music as compared to silence were associated with ratings of "disturbing." The latter correlation indicated that large $\mathrm{O}_{1}$ beta differences were associated with "exciting" ratings. The EEG difference scores for nonmusicians were also relatively weak predictors of subjective reactions. Three of the correlations did, however, reach significance. Difference scores for $\mathrm{O}_{1}$ theta correlated with the "unfamiliar-familiar" scale $(\mathrm{r}=.57, \mathrm{~N}=24$, $\mathrm{p}<.01)$ and also with the "relaxed-tense" scale $(\mathrm{r}=-.51, \mathrm{~N}=24, \mathrm{p}<.05)$. Large $\mathrm{O}_{1}$ theta differences were associated with ratings of familiarity with the music and ratings of being relaxed. The correlation of $\mathrm{O}_{2}$ alpha differences for nonmusicians with the "unfamiliar-familiar" scale was also found to be significant $(\mathrm{r}=-.55, \mathrm{~N}=24, \mathrm{p}<.01)$. This correlation indicated that large $\mathrm{O}_{2}$ alpha differences were associated with ratings of unfamiliarity with the music.

\section{DISCUSSION}

The results of this research provided evidence that self-reports of attentiveness during music listening, familiarity with the music, and emotional reactions to music are all correlated moderately to substantially with various EEG measures of brainwave activity. The existence of self-report/EEG correlations suggests that EEG techniques may provide a useful method of linking electrophysiological measures of brain activity to cognitive, affective, and perhaps even aesthetic reactions to music. The implications of the finding that subjective reactions to music and EEG measures of brain activity are related are diverse and beyond the scope of this paper, but an immediate and important conclusion is that EEG techniques may be useful in increasing our understanding of brain mechanisms which accompany subjective reactions to music.

An inspection of the results of the present research indicates that self-reports of how attentively the subjects listened to the music were correlated with the

Table 5

Mean Difference Scores Between Music and Silence for EEG Frequencies in Musicians and Nonmusicians

\begin{tabular}{|c|c|c|c|c|c|c|c|}
\hline \multirow[b]{2}{*}{ Site } & \multirow[b]{2}{*}{ Band } & \multicolumn{3}{|c|}{ Musicians } & \multicolumn{3}{|c|}{ Nonmusicians } \\
\hline & & $\overline{\mathbf{x}}_{\mathbf{d}}$ & $\mathbf{s}_{\mathbf{d}}$ & $\mathrm{t}$ & $\overline{\mathbf{x}}_{\mathrm{d}}$ & $\mathbf{s}_{\mathbf{d}}$ & $\mathrm{t}$ \\
\hline \multirow{4}{*}{$0_{1}$} & Delta & 1.76 & 3.5 & $2.46 * *$ & 2.69 & 5.7 & $2.32 * *$ \\
\hline & Theta & 2.16 & 4.9 & $2.16 * *$ & 2.14 & 6.2 & 1.69 \\
\hline & Alpha & -3.09 & 7.4 & $2.04 *$ & -7.80 & 9.3 & $4.10 \dagger \dagger$ \\
\hline & Beta & .63 & 7.8 & .39 & 3.82 & 8.5 & $2.19^{* *}$ \\
\hline \multirow{4}{*}{$0_{2}$} & Delta & .91 & 3.1 & 1.44 & 5.02 & 5.6 & $4.40 \dagger \dagger$ \\
\hline & Theta & 3.64 & 6.5 & $2.74 \dagger$ & 2.75 & 5.5 & $2.45 * *$ \\
\hline & Alpha & -4.82 & 9.8 & $2.40 * *$ & -4.67 & 8.8 & $2.59 \dagger$ \\
\hline & Beta & 1.99 & 7.3 & 1.33 & -.38 & 12.1 & .15 \\
\hline
\end{tabular}

Note $-N=24$.

${ }^{*} p<.10 \quad t p<.02$

$* * p<.05 \quad t+p<.01$ 
percentage of delta, theta, and alpha activity in the EEG records. In the case of delta and theta activity, self-reports of paying little attention to the music were related to both high theta- and high delta-wave production. Opposite results were obtained for alpha waves, where listening attentively to the music was related to high alpha production. It is well known that the frequency of the EEG appears to vary on a continuum corresponding to level of behavioral arousal. Increased levels of arousal are associated with increases in the dominant frequency of the EEG. It is conceivable that, in the present study, subjects paying more attention to the music were also experiencing higher levels of activation or arousal which mediated an increase in EEG frequencies. These subjects thus showed fewer slow waves in the delta and theta bandwidths and more activity in the relatively faster alpha bandwidth.

Duffy (1972) has suggested that theta waves may represent an exception to the relation between fast EEG frequencies and high levels of arousal, since these waves are frequently found in situations such as high levels of anxiety where waves of high frequency would be expected. The present study found consistent relationships between percent theta activity and self-reports of paying little attention to the music, indicating that the situations where theta activity was present were consistent with the predictions derived from the behavioral arousal hypothesis. The presence of a correlation between theta activity and self-reports of tension is also consistent with the behavioral arousal hypothesis. Subjects reporting feeling relaxed by the music tended to be high theta producers, and large differences in theta activity between music and silence were also found to be repeatedly associated with ratings of being more "relaxed" during the music.

Lindsley and Wicke (1974) and Walter (1953) have suggested that there is an association between the EEG slow-wave activity and emotional experience. The finding of correlations at the left hemisphere between evaluations of the classical music as "unpleasant" and high delta wave production is consistent with the idea that slow-wave EEG activity may be related to emotional reactions.

Both theta and alpha activity were found to correlate significantly with self-reports of familiarity with the music. Subjects reporting high familiarity with the music produced higher levels of theta activity, while reports of low familiarity with the music were associated with high alpha production. EEG difference scores were also found to be associated with ratings of familiarity with the music. Large $\mathrm{O}_{1}$ theta differences correlated with ratings of increased familiarity with the music, as did large differences in $\mathrm{O}_{2}$ beta activity. Large differences in $\mathrm{O}_{2}$ alpha between music and silence were found also to be correlated with reports of unfamiliarity with the music. Large discrepancies in beta activity during music also correlated with the familiarity scale. These results may relate to the EEG literature, which suggests that stimulus novelty causes an increase in EEG frequency but the effect habituates with repeated stimulus presentation (Grossman, 1973). Subjects having higher degrees of familiarity would thus be expected to show relatively more slow activity, as was observed in the present study for theta activity, since the musical stimulus was less novel for these subjects. On the other hand, subjects having less familiarity with the music would be expected to show more fast-wave production, since the slower waves might be expected to be blocked by the novelty of the sensory stimulation. The present study did observe a substantial correlation between reports of low familiarity with the music and alpha production. Although alpha waves are, indeed, faster than theta activity, one might have expected to observe more substantial correlations between direct measures of fast beta activity and reports of familiarity; however, large discrepancies in beta during music and silence was found to correlate with familiarity ratings.

It is interesting to note that most of the significant correlations between EEG activity and self-reports were contributed by the classical rather than the rock music. The reasons for this difference remains unclear. The two musical selections differed in many respects. The rock music was, for example, highly repetitive, bordering on being monotonous. It is possible that the strong repetitive rhythmic nature of the rock music may have been more effective than the classical music in "driving" the EEG, so that the EEG response was related more closely to the physical characteristics of the sound, thus obscuring any relationship with subjective reactions to the music. Such an interpretation remains entirely speculative, and future research exploring the limits of subjective report/EEG correlations for differing musical stimuli is clearly required.

An additional finding of interest in the present research was that the majority of the significant correlations between EEG measures and self-reports occurred among the nonmusicians. This finding may be helpful in resolving the differences between the present report and an earlier study (Wagner, 1975b) reporting no relationship between alpha production at the temporal lobes and verbal reports of attentiveness. In addition to the differences in recording locations, Wagner used only subjects selected from a school of music. It is possible that the failure, in the present study, to find significant relationships between measures among the musician subjects essentially represents a replication of the Wagner findings. The chief question, of course, is why musically naive subjects show correlations between 
their subjective reactions to music while more musically sophisticated subjects do not. One of the major limitations of the product-moment correlation coefficient is that a truncated range of scores on an input variable will have the effect of lowering the magnitude of the resulting correlation (McNemar, 1962). Thus, a sample of scores having restrictions in the range of scores in either one or both variables will yield a relatively low correlation. We propose that this factor was operating in the present study in such a way that the musically sophisticated subjects showed more homogeneity of variance in their EEG scores than the musically naive subjects. This interpretation is supported by the observation that, for all eight EEG measures, the variance of the scores was lower in every case for the musicians as compared to the greater variability of scores present in every case for the nonmusicians. The significance of these differences in variability were tested using the sign test (Siegel, 1956). The sign test yielded a $\mathrm{p}<.01$, indicating that the nonmusicians showed significantly more variability in their EEG measures than did the musicians. We do not wish to imply, by this discussion, that the lower variability among the musicians represents some sort of statistical artifact. One might expect to observe a more homogeneous sample of subjects among a group of advanced music students than among a group of students drawn from a first-year psychology course. It is also possible that the smaller variance in brain response in the musically sophisticated subjects is, in some way, a reflection of the specialized training in music and music appreciation in these individuals. Additional research would be useful in the study of these questions.

In conclusion, the present research has demonstrated a number of moderate to substantial correlations between subjective reactions to music and EEG measures taken during music listening. It is interesting to note that much of the prior work in this area has centered exclusively on alpha activity with negative results. The present study found that the majority of significant correlations were between subjective reactions and direct measures of EEG activity in the slower theta and delta bandwidths. These findings may suggest that future research efforts should not exclude, and perhaps should emphasize, using theta and delta activity among the dependent measures. On the other hand, our results also suggest that music minus silence scores in the alpha and beta bandwidths are correlated with various subjective reactions to music more substantially than music minus silence changes in the slower bandwidths. The present study indicates that EEG techniques may prove helpful in increasing our understanding of brain mechanisms related to music perception as well as electrophysiological patterns associated with emotional and aesthetic reactions to music. The presence of moderate to substantial correlations between EEG measures and subjective reactions to musical stimuli suggests that it may ultimately be possible to account for sizabie segments of the variance of aesthetic reactions in terms of EEG measures of brain activity.

\section{REFERENCE NOTE}

1. Walker, J. L., \& Ehnes, A. EEG lateralization in musicians and nonmusicians during music perception. Manuscript submitted for publication, 1977.

\section{REFERENCES}

Berger, H. Überdas Elektrenkephalogram des Menschen. Archiv für Psychiatrie und Nervenkrankheiten, 1929, 87, 527-570.

Dixon, W. J. (Ed.) Biomedical computer programs. Berkeley: University of California Press, 1973.

DufFY, E. Activation. In N. S. Greenfield \& R. A. Sternbach (Eds.), Handbook of psychophysiology. New York: Holt, 1972. Pp. 577-622.

Grossman, S. P. Essentials of physiological psychology. New York: Wiley, 1973.

Lindsley, D. B., \& WICKE, J. D. The electroencephalogram: Autonomous electrical activity in man and animals. In R. F. Thompson \& M. M. Patterson (Eds.), Bioelectric recording technique. Part B: Electroencephalography and human brain potentials. New York: Academic Press, 1974. Pp. 3-83.

McNemar, Q. Psychological statistics (3rd ed.). New York: Wiley, 1962.

ShaG ASs, C. Electrical activity of the brain. In N. S. Greenfield \& R. A. Sternback (Eds.), Handbook of psychophysiology. New York: Holt, Rinehart, \& Winston, 1972. Pp. 263-328.

SIEGEL, S. Nonparametric statistics for the behavioral sciences. New York: McGraw-Hill, 1956.

Sulg, I. A. Manual EEG analysis. Acta Neurologica Scandinavica, 1969, 45, 431-458.

WAGNER, M. J. Brainwaves and biofeedback: A brief historyimplications for music research. Journal of Music Therapy. 1975, 12, 46-58. (a)

WAGNER, M. J. Effect of music and biofeedback on alpha brainwave rhythms and attentiveness. Journal of Research in Music Education. 1975, 23, 3-13. (b)

W ALTER. W. G. The living brain. New York: Norton, 1953.

(Received for publication June 6, 1977; revision accepted October 11, 1977.) 